\title{
OPEN The effects of short-term light exposure on subjective affect and comfort are dependent on the lighting time of day
}

\author{
Lijun Chen ${ }^{1,2}$, Fang-Fang Yan ${ }^{1,2}$, Shuhan Fan ${ }^{1,2}$, Yifan Wu ${ }^{1,2}$, Jia Yang ${ }^{1,2}$, Hua Yang ${ }^{3}$ \& \\ Chang-Bing Huang ${ }^{1,2}$
}

Light, one of the key environmental components for both life and work, played significant role in subjective feelings (e.g. affect and comfort), but the exact effects and mechanisms were still to be determined. The present study screened thirty healthy adults ( 13 females, $22.45 \pm 3.26$ years) and examined subjective affect and comfort under short-term white lights with different combination of correlated color temperature (CCT) and illuminance at different times of day (e.g. morning, afternoon, and evening). Our results showed a significant interaction between illuminance level and time-of-day on subjective comfort. Participants felt more comfortable under $50 \mathrm{~lx}$ and $100 \mathrm{~lx}$ instead of $500 \mathrm{~lx}$ in the evening, and more comfortable under $500 \mathrm{~lx}$ in the morning and afternoon. In addition, a positive correlation between illuminance and comfort in the morning and a negative correlation between them in the evening were found. No significant effect of CCT on any subjective feeling was revealed. Our results necessitate the consideration of time-of-day in understanding lighting effects and application of healthy lighting in daily life.

Apart from significant role in inducing visual effects, light also plays a critical role in non-visual functions, e.g. subjective affect and comfort ${ }^{1}$. Since Kripke et al. (1983) found that exposure with high-intensity light can reduce the depression symptoms in patients with depressive disorder ${ }^{2}$, light had been widely used to treat affective disorder in clinical practice ${ }^{3-5}$. In recent years, researches have also suggested significant effects of light on subjective affect and comfort in normal population ${ }^{1,6-8}$, which provided possibilities for using light to improve subjective well-being in daily life and attracted sustainable attention in the past decades.

Illuminance and spectral distribution are two commonly studied properties of light in modulating subjective affect and comfort, dated back to the influential study by Kruithof who presented a graph to show preferred interior lighting conditions in terms of illuminance and correlated color temperature ${ }^{9}$. According to the Kruithof's rule, people felt more comfortable and pleasing at low illuminance and low CCT light condition and at high illuminance and high CCT condition. The Kruithof's rule was widely applied in interior lighting design, although subsequent studies were highly controversial ${ }^{10-14}$. For example, Park et al. (2013) found a significant effect of illuminance but not CCT on pleasant feeling, at which subjects felt more pleasant at high (600 lx) instead of low illuminance (300 lx) condition ${ }^{13}$. On the contrary, Sunwoo et al. (2017) found similar effect of high and low illuminance (700 lx vs. $300 \mathrm{~lx}$ ) on affect under short-term light exposure ( several minutes). In the study of the relationship between spatial distribution of light and subjective affect and comfort, lower CCT was endorsed by some researches e.g. ${ }^{1,15-17}$ while higher CCT was favored by others' e.g. ${ }^{7,18-20}$. For example, Sunwoo et al. (2017) found a significantly positive effect of lower CCT $(3000 \mathrm{~K})$ on subjective feelings (e.g. felt more comfort and happiness), as opposed to $6500 \mathrm{~K}$, but Chellappa et al. (2011) found that exposure to a higher CCT condition $(6500 \mathrm{~K})$ for 2 hours before bedtime strongly suppressed the secretion of melatonin and enhanced subjective well-being (e.g. mood, tension and physical comfort), as opposed to the $2500 \mathrm{~K}$ CCT condition. In addition, many studies failed to find the effect of CCT on subjective comfort and affect ${ }^{13,21}$.

Factors such as lighting duration and timing may contribute to the conflicting results. At one hand, lighting duration ranged from several minutes ${ }^{1}$ to hours ${ }^{22}$ in previous laboratory studies and could last even several

${ }^{1}$ CAS Key Laboratory of Behavioral Science, Institute of Psychology, Chinese Academy of Sciences, Beijing 100101, China. ${ }^{2}$ Department of Psychology, University of Chinese Academy of Sciences, Beijing 100049, China. ${ }^{3}$ Institute of Semiconductors, Chinese Academy of Sciences, Beijing 100083, China. ${ }^{\square}$ email: yanff@psych.ac.cn; huangcb@ psych.ac.cn 
weeks in field studies ${ }^{18}$. On the other hand, subjects can be exposed to light in the morning (e.g. 08:00; ${ }^{23}$ ), afternoon (e.g. 15:00;13), and/or evening (e.g. before sleep; $\left.{ }^{19}\right)$. Anecdotal evidence has suggested different timing of lighting may have reverse effect, e.g. advancing or delaying circadian phase $\mathrm{e}^{24}$. Also, the majority of researches about the effects of light were carried out together with cognitive tasks, e.g. go/no-go, $N$-back working memory, Psychomotor Vigilance Task, Flanker task, long-term memory, and emotional judgment task ${ }^{13,16,17,22,25}$. The tasks performed during light exposure and associated (potential) fatigue might also confound the effects of light on subjective affect and comfort ${ }^{26}$.

Previous studies had confirmed the effectiveness of short-term light exposure on modulating physical and psychological processes ${ }^{8,13,27,28}$. In the current study, we examined the effects of short-term light exposure with different combination of illuminance, CCT, and exposed time of day on subjective affect and comfort to minimize the confounding influence of fatigue on subjective feelings. We also spared subjects during light exposure, aiming to isolate "pure" effects of light on subjective affect and comfort. We found significant interaction between the illuminance level, but not CCT, and time-of-day on subjective comfort. Our results suggested that research of lighting effects and design of healthy lighting should take into account the influence of lighting time of the day.

\section{Results}

The results of multivariate analysis of variance (MANOVA) revealed significant main effect of time-of-day on arousal $\left(\mathrm{F}(2,241)=5.572, p=0.004\right.$, Partial $\left.\eta^{2}=0.044\right)$ and interaction of illuminance and time-of-day on comfort $\left(\mathrm{F}(4,241)=3.980, p=0.004\right.$, Partial $\left.\eta^{2}=0.062\right)$. All other interactions were not significant (Table 1$)$.

For the effect of time-of-day on arousal level, post-hoc tests found that participants felt more arousal in the morning $(4.296 \pm 0.130$, mean \pm s.e.; $95 \%$ Confidence Interval $(\mathrm{CI})=[4.037,4.555] ; p=0.011)$ and evening $(4.416 \pm 0.132,95 \% \mathrm{CI}=[4.152,4.679] ; p=0.002)$ than in the afternoon $(3.756 \pm 0.132,95 \% \mathrm{CI}=[3.496,4.017]$; Fig. 1).

The simple effect of illuminance on comfort was found in the evening session $(\mathrm{F}(2,241)=6.890, p=0.001$, Partial $\eta^{2}=0.054$; Table 2). Post-hoc tests found that participants felt more comfortable under $50 \mathrm{~lx}(5.435 \pm 0.209$, $95 \% \mathrm{CI}=[5.001,5.869] ; p=0.003)$ and $100 \mathrm{~lx}(5.5438 \pm 0.157,95 \% \mathrm{CI}=[5.112,5.763] ; p=0.007)$ than $500 \mathrm{~lx}$ $(4.313 \pm 0.327,95 \% \mathrm{CI}=[3.637,4.988]$; Fig. 2). The simple effects of time-of-day on comfort were found at $50 \mathrm{~lx}$ $\left(\mathrm{F}(2,241)=3.602, p=0.029\right.$, Partial $\left.\eta^{2}=0.029\right)$ and $500 \mathrm{~lx}\left(\mathrm{~F}(2,241)=5.960, p=0.003\right.$, Partial $\eta^{2}=0.047$; Table 2). Post-hoc tests showed that subjects felt more comfortable in the evening $(5.435 \pm 0.209,95 \% \mathrm{CI}=[5.001,5.869])$, as opposed to morning $(4.907 \pm 0.191,95 \% \mathrm{CI}=[4.516,5.299] ; p=0.031)$ under $50 \mathrm{~lx}$ and more comfortable in the morning $(5.556 \pm 0.202,95 \% \mathrm{CI}=[5.140,5.971] ; p=0.042)$ and afternoon $(5.667 \pm 0.150,95 \% \mathrm{CI}=[5.364$, 5.970]; $p=0.002)$, as opposed to evening (4.313 $\pm 0.327,95 \% \mathrm{CI}=[3.637,4.988])$ under $500 \mathrm{~lx}$ (Fig. 2).

To further explore the relationship between illuminance and comfort, a Spearman correlation analysis was performed. Interestingly, a positive correlation $(\mathrm{r}=0.280, p=0.011)$ was found between illuminance and comfort in the morning while a significantly negative correlation $(\mathrm{r}=-0.320, p=0.006)$ between them in the evening (Fig. 3).

\section{Discussion}

A significant main effect of time-of-day on arousal level was found in the current study. We didn't find any significant effect of CCT and illuminance on the affective states (e.g. valence, arousal, dominance) under shortterm light exposure (e.g. $3 \mathrm{~min}$ ). Interestingly, a significant interaction between illuminance and time-of-day on subjective comfort was detected. Further analysis revealed a dissociated relationship between illuminance and comfort in the morning and evening.

Previous studies have also revealed significant effect of time-of-day on subject's arousal level ${ }^{29,30}$. For example, the work performed by Parrott who assessed the arousal in different groups (e.g. sedative smokers, stimulant smokers, nicotine deprived smokers and non-smokers) at different times of day showed that feelings of arousal were significantly affected by time. The result that all groups started the day after waking with low arousal but peaked at different times suggested that even though the changing patterns over time differed between subgroups, the arousal was significantly affected by time of day ${ }^{29}$. Our result that participants felt more arousal in the morning and evening also suggested this point.

In the present study, the effect of illuminance, instead of CCT, on subjective comfort was found to be significant. Our results were inconsistent with the Kruithof's rule that suggested the preferred interior lighting conditions with combinations of illuminance and $\mathrm{CCT}^{9}$ while partially consistent with some other researches that only found significant effect of illuminance on subjective comfort. According to Boyce's work, people felt more pleasant and comfortable in light condition with higher illuminance level while the CCT didn't show significant effect $^{10}$. Fotios revised the Kruithof's curve and suggested that the variation in CCT has a negligible effect on subjective pleasure and the one condition to avoid is low illuminance less than $300 \mathrm{~lx}^{12}$. On the other hand, our results indicated the effects of illuminance on subjective comfort was affected by the lighting time of the day: subjects felt more comfortable in higher illuminance level in the morning, and low illuminance in the evening.

Light is one of the major cues to discriminate day and night and keep normal circadian rhythm ${ }^{31,32}$. Exposure to less light at daytime and bright light in the evening can impact circadian rhythm negatively ${ }^{33,34}$. We argue that light echoed with natural circadian may inherently link to more positive effects ${ }^{13}$ and our observation of the significant interaction of illumination and time of day on affect and subjective comfort necessitated the consideration of temporal aspects of light exposure in the understanding of lighting effects and the design of healthy lighting.

To minimize the potential confounding of fatigue on subjective feelings, the present study adopted a shortterm light exposure. However, compared to short-term exposure, long-term exposure to light might have a different or even a reverse effect on cerebral activity. For example, a research conducted in 2017 found that short-term 


\begin{tabular}{|c|c|c|c|c|c|}
\hline & df & MS & $\mathbf{F}$ & $p$ & Partial $\eta^{2}$ \\
\hline \multicolumn{6}{|l|}{ CCT } \\
\hline Valence & 2 & 2.291 & 1.670 & 0.190 & 0.014 \\
\hline Arousal & 2 & 0.195 & 0.115 & 0.892 & 0.001 \\
\hline Dominance & 2 & 0.906 & 0.411 & 0.664 & 0.003 \\
\hline Comfort & 2 & 0.401 & 0.729 & 0.483 & 0.006 \\
\hline \multicolumn{6}{|l|}{ Illuminance } \\
\hline Valence & 2 & 0.775 & 0.565 & 0.569 & 0.005 \\
\hline Arousal & 2 & 2.242 & 1.318 & 0.269 & 0.011 \\
\hline Dominance & 2 & 1.140 & 0.517 & 0.597 & 0.004 \\
\hline Comfort & 2 & 0.553 & 1.006 & 0.367 & 0.008 \\
\hline \multicolumn{6}{|l|}{ Time-of-day } \\
\hline Valence & 2 & 0.557 & 0.406 & 0.667 & 0.003 \\
\hline Arousal & 2 & 9.478 & 5.572 & 0.004 & 0.044 \\
\hline Dominance & 2 & 6.540 & 2.966 & 0.053 & 0.024 \\
\hline Comfort & 2 & 1.463 & 2.663 & 0.072 & 0.022 \\
\hline \multicolumn{6}{|c|}{ CCT ${ }^{*}$ Illuminance } \\
\hline Valence & 4 & 0.193 & 0.141 & 0.967 & 0.002 \\
\hline Arousal & 4 & 0.316 & 0.186 & 0.946 & 0.003 \\
\hline Dominance & 4 & 0.338 & 0.153 & 0.961 & 0.003 \\
\hline Comfort & 4 & 0.130 & 0.237 & 0.917 & 0.004 \\
\hline \multicolumn{6}{|c|}{ CCT ${ }^{*}$ Time-of-day } \\
\hline Valence & 4 & 0.034 & 0.025 & 0.999 & 0.000 \\
\hline Arousal & 4 & 0.955 & 0.561 & 0.691 & 0.009 \\
\hline Dominance & 4 & 0.177 & 0.080 & 0.988 & 0.001 \\
\hline Comfort & 4 & 0.147 & 0.268 & 0.898 & 0.004 \\
\hline \multicolumn{6}{|c|}{ Illuminance ${ }^{*}$ Time-of-day } \\
\hline Valence & 4 & 0.499 & 0.364 & 0.834 & 0.006 \\
\hline Arousal & 4 & 0.133 & 0.078 & 0.989 & 0.001 \\
\hline Dominance & 4 & 0.625 & 0.283 & 0.889 & 0.005 \\
\hline Comfort & 4 & 2.186 & 3.980 & 0.004 & 0.062 \\
\hline \multicolumn{6}{|c|}{ CCT $^{\star}$ Illuminance ${ }^{*}$ Time-of-day } \\
\hline Valence & 8 & 0.442 & 0.323 & 0.957 & 0.011 \\
\hline Arousal & 8 & 0.594 & 0.349 & 0.946 & 0.011 \\
\hline Dominance & 8 & 0.187 & 0.085 & 1.000 & 0.003 \\
\hline Comfort & 8 & 0.241 & 0.438 & 0.897 & 0.014 \\
\hline
\end{tabular}

Table 1. MANOVA analysis of CCT, illuminance, and time-of-day on affect and comfort. MS: mean square; F, $p$, and partial $\eta^{2}$ refer to the F value, significance level, and effect size from the MANOVA analysis, respectively.

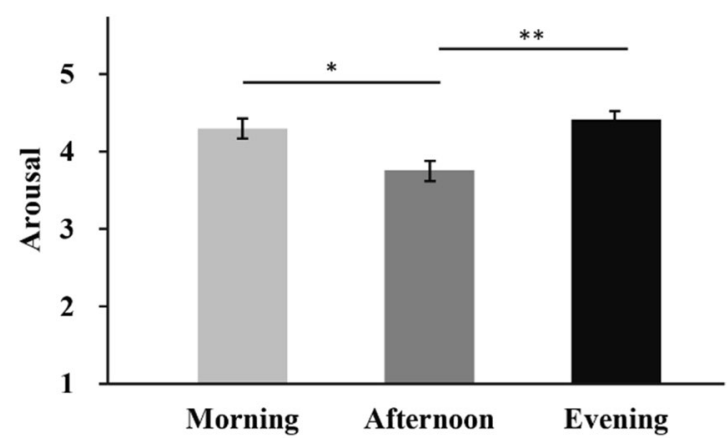

Figure 1. Pairwise comparisons for arousal level among different time-of-day. ${ }^{\star} p<0.05 ;{ }^{* *} p<0.01$. 


\begin{tabular}{|l|l|l|l|l|l|}
\hline & df & MS & F & $\boldsymbol{p}$ & ${\text { Partial } \boldsymbol{\eta}^{2}}^{\mid}$ \\
\hline Time-of-day \\
\hline Morning & 2 & 0.785 & 1.430 & 0.241 & 0.012 \\
\hline Afternoon & 2 & 0.137 & 0.250 & 0.779 & 0.002 \\
\hline Evening & 2 & 3.785 & 6.890 & 0.001 & 0.054 \\
\hline Illuminance \\
\hline $50 \mathrm{~lx}$ & 2 & 1.979 & 3.602 & 0.029 & 0.029 \\
\hline $100 \mathrm{~lx}$ & 2 & 0.532 & 0.968 & 0.381 & 0.008 \\
\hline $500 \mathrm{~lx}$ & 2 & 3.274 & 5.960 & 0.003 & 0.047 \\
\hline
\end{tabular}

Table 2. The simple effect of illuminance and time-of-day on comfort. MS: mean square; $\mathrm{F}, p$, and partial $\eta^{2}$ refer to the F value, significance level, and effect size from the MANOVA analysis, respectively.

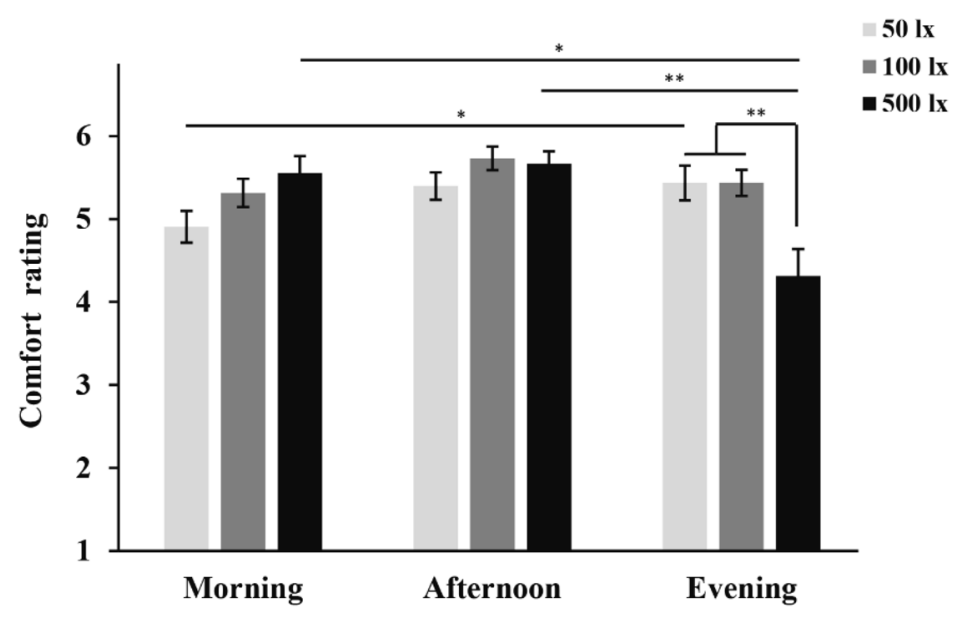

Figure 2. Pairwise comparisons among comfort ratings under different illuminance levels and time-of-day. ${ }^{*} p<0.05 ;{ }^{* *} p<0.01$.

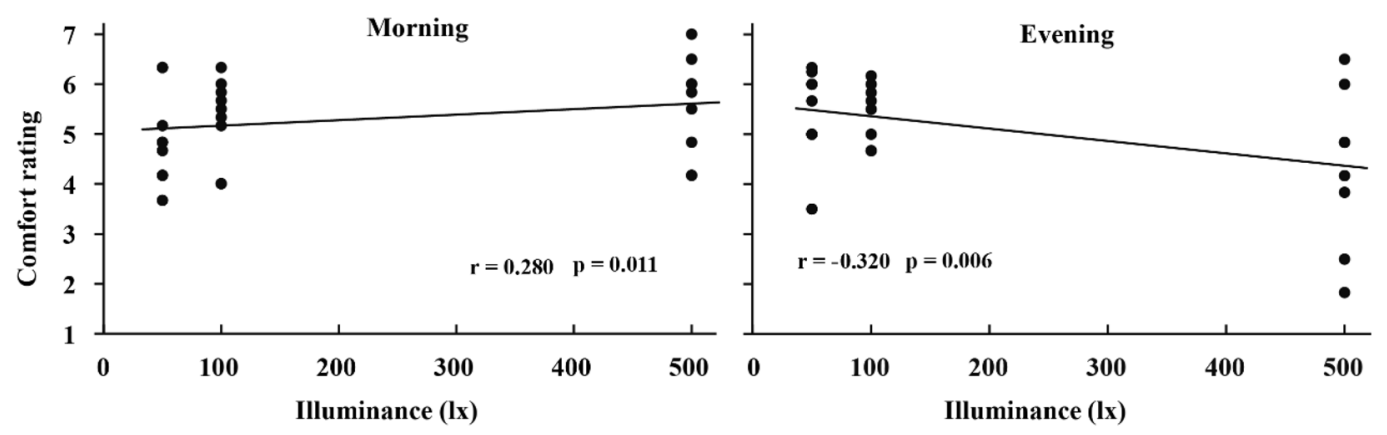

Figure 3. Correlation between illuminance and comfort in the morning (left) and the evening (right).

exposure to monochromatic blue light decreased lower-frequency electroencephalogram bands while long-term exposure induced an increase in lower frequency bands ${ }^{35}$. The effects of long-term light on subjective affect and comfort should be investigated in future.

\section{Conclusions}

In summary, the present study reported a significant interaction between light illuminance and time-of-day on subjective comfort. Our results contribute to the understanding of light effect and will be of interest to the design of healthy lighting environment in daily work and life. 

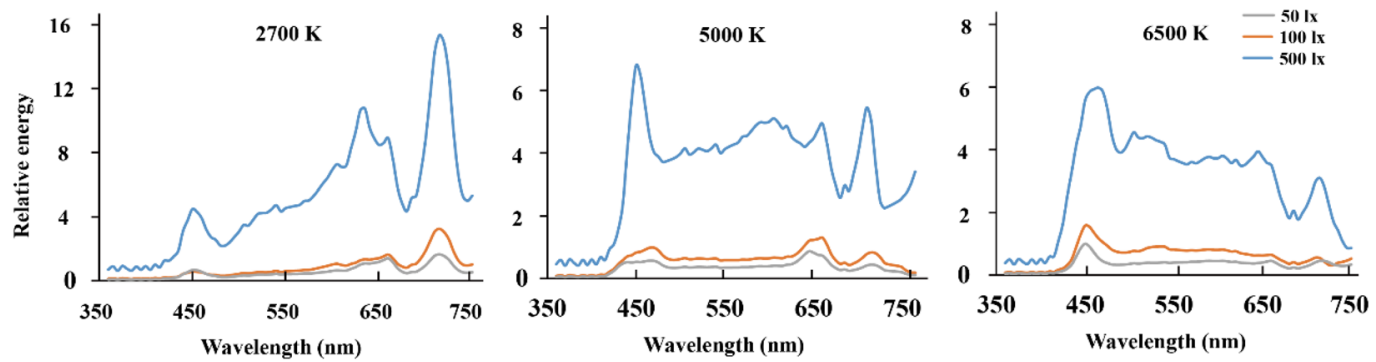

Figure 4. Relative spectral distribution of different light conditions: left: $2700 \mathrm{~K}$, middle: $5000 \mathrm{~K}$; right: $6500 \mathrm{~K}$; Gray: 50 lx; Orange: 100 lx; Blue: 500 lx.

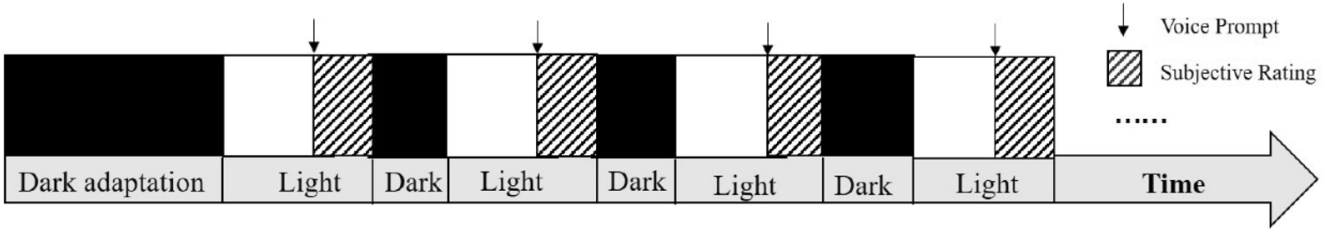

Figure 5. Testing sequence. Subjects were exposed to different lights one after another with a 2-min dark interval $(<0.01 \mathrm{~lx})$. After light exposure, a brief voice (indicated by arrow) prompted participants to rate their current subjective feelings within 1 min under the same light condition.

\section{Methods}

Participants. Thirty healthy adults, aged 18 to 31 years ( 13 females, $22.45 \pm 3.26$ years), participated in the study and received monetary compensation. All subjects had normal or corrected-to-normal visual acuity, normal color vision, and were free of ocular diseases. All participants gave their written informed consents before experiment began. The study was approved by the local ethical committee of Institute of Psychology, Chinese Academy of Sciences and all research activities were adhered to the principles of the Declaration of Helsinki.

Study design. The experiment employed a $3 \times 3 \times 3$ mixed-group design with three independent variables: illuminance (50 lx vs. $100 \mathrm{~lx}$ vs. $500 \mathrm{~lx}$, at $0.75 \mathrm{~m}$ height table level) and CCT (2,700 K vs. 5,000 K vs. 6,500 K) as within-subject factors, and time-of-day (morning vs. afternoon vs. evening) as between-subjects factor. The relative spectral distribution of the nine light conditions was shown in Fig. 4. The morning session started at 9:30 a.m., the afternoon session started at 3:00 p.m., and the evening session started at 7:30 p.m. Constrained by the availableness of subjects' schedule, nine, thirteen, and eight subjects were assigned to the morning, afternoon and evening sessions, respectively. Each participant went through all nine light conditions and every condition was repeated twice. The testing order of all light conditions was counterbalanced across subjects.

For each subject, after 5-min dark adaptation $(<0.01 \mathrm{~lx}$; Fig. 5), different lights were presented one after another with a 2 -min dark $(<0.01 \mathrm{~lx})$ interval in-between. In each trial, participants were exposed to one light condition for $3 \mathrm{~min}$, during which subjects were asked to sit still in the first $2 \mathrm{~min}$ and rate their current subjective feelings after a voice prompt in the last $1 \mathrm{~min}$. Subjects were informed to sit quietly without closing eyes during exposure.

Environmental setting. The study was carried out in a windowless room, with a size of $4.36 \times 4.03 \times 2.70 \mathrm{~m}$. The walls and ceiling of the room were white. Six identical custom-made LED lighting devices, with spectrum ranged from 380 to $780 \mathrm{~nm}$ and surface homogenized by scatter plate, were mounted onto the ceiling. Each LED lighting device consisted of 22 classes of monochrome LEDs and two classes of white LEDs. The intensity of each class of the LED can be adjusted for different combinations of spectral intensity with control accuracy better than $1 \%$. The device can simulate most natural lighting conditions, in which the desktop illuminance of typical CIE white illuminant can reach $750 \mathrm{~lx}$ and correlated color temperature can cover from 1800 to $7500 \mathrm{~K}$.

Assessment of subjective feelings. Subjective affect states, comfort, and eye fatigue were evaluated under each light condition. Participants rated their affects in terms of valence, arousal, and dominance with 9-point Self-Assessment Manikin Test ${ }^{36}$, with 1 for unpleasant, calm, and controlled state, and 9 for pleasant, excited, and in-control state. The subjective comfort and eye fatigue under each light condition were rated via a 7-point scale, with 1 for discomfort or non-fatigue to 7 for comfort or eye fatigue.

Statistical analysis. All analyses were performed by SPSS version 20 (IBM, USA). The rating scores of subjective feeling for each light condition were averaged for each subject. The effects of time of day (morning vs. afternoon vs. evening; between-subject factor), CCT (2700 K vs. $5000 \mathrm{~K}$ vs. $6500 \mathrm{~K}$; within-subject factor), and 
illuminance ( 50 lx vs. 100 lx vs. 500 lx; within-subject factor), and interactions of the three factors on subjective feelings, e.g. valence, arousal, dominance, and comfort, were computed using multivariate analysis of variance (MANOVA), with eye fatigue as covariate. Post-hoc tests of simple effects were performed with Bonferroni correction $^{37}$. Non-parametric correlation analysis was performed to test the relationship between illuminance and comfort in different times of day.

\section{Data availability}

The data that support the findings of this study are available from the corresponding author upon reasonable request.

Received: 29 November 2020; Accepted: 29 December 2020

Published online: 28 January 2021

\section{References}

1. Sunwoo, J.-S. et al. Differential effect of light emitting diode light on electroencephalographic oscillations in young and old healthy subjects. J. Sleep Med. 14, 61-69. https://doi.org/10.13078/jsm.17009 (2017).

2. Kripke, D. F., Risch, S. C. \& Janowsky, D. Bright white-light alleviates depression. Psychiat. Res. 10, 105-112. https://doi. org/10.1016/0165-1781(83)90109-9 (1983).

3. Anderson, J. L. et al. Are short (blue) wavelengths necessary for light treatment of seasonal affective disorder?. Chronobiol. Int. 33, 1267-1279. https://doi.org/10.1080/07420528.2016.1207660 (2016).

4. Meyerhoff, J., Young, M. A. \& Rohan, K. J. Patterns of depressive symptom remission during the treatment of seasonal affective disorder with cognitive-behavioral therapy or light therapy. Depress Anxiety 35, 457-467. https://doi.org/10.1002/da.22739 (2018).

5. Goel, N., Terman, M., Terman, J. S., Macchi, M. M. \& Stewart, J. W. Controlled trial of bright light and negative air ions for chronic depression. Psychol. Med. 35, 945-955. https://doi.org/10.1017/S0033291705005027 (2005).

6. Munch, M. et al. Bright light delights: Effects of daily light exposure on emotions, rest-activity cycles, sleep and melatonin secretion in severely demented patients. Curr. Alzheimer Res. 14, 1063-1075. https://doi.org/10.2174/1567205014666170523092858 (2017).

7. Viola, A. U., James, L. M., Schlangen, L. J. M. \& Dijk, D.-J. Blue-enriched white light in the workplace improves self-reported alertness, performance and sleep quality. Scand. J. Work Environ. Health 34, 297-306. https://doi.org/10.5271/sjweh.1268 (2008).

8. Han, S. \& Lee, D. The effects of treatment room lighting color on time perception and emotion. J. Phys. Ther. Sci. 29, 1247-1249. https://doi.org/10.1589/jpts.29.1247 (2017).

9. Kruithof, A. A. Tubular luminescence lamps for general illumination. Philips Tech. Rev. 6(3), 65-96 (1941).

10. Boyce, P. R. \& Cuttle, C. Effect of correlated colour temperature on the perception of interiors and colour discrimination performance. Light. Res. Technol. 22, 19-36. https://doi.org/10.1177/096032719002200102 (1990).

11. Davis, R. G. \& Ginthner, D. N. Correlated color temperature, illuminance level, and the Kruithof Curve. J. Illum. Eng. Soc. 19, 27-38. https://doi.org/10.1080/00994480.1990.10747937 (1990).

12. Fotios, S. A revised Kruithof graph based on empirical data. Leukos 13, 3-17. https://doi.org/10.1080/15502724.2016.1159137 (2016).

13. Park, J. Y., Ha, R. Y., Ryu, V., Kim, E. \& Jung, Y. C. Effects of color temperature and brightness on electroencephalogram alpha activity in a polychromatic light-emitting diode. Clin. Psychopharmacol. Neurosci. 11, 126-131. https://doi.org/10.9758/ cpn.2013.11.3.126 (2013).

14. Bodmann, H. W. Quality of interior lighting based on luminance. Trans. Illumin. Eng. Soc. 32, 22-40. https://doi.org/10.1177/14771 5356703200104 (1967).

15. Denk, E., Jimenez, P. \& Schulz, B. The impact of light source technology and colour temperature on the well-being, mental state and concentration of shop assistants. Light. Res. Technol. 47, 419-433. https://doi.org/10.1177/1477153514532280 (2015).

16. Ru, T., de Kort, Y. A., Smolders, K. C., Chen, Q. \& Zhou, G. Non-image forming effects of illuminance and correlated color temperature of office light on alertness, mood, and performance across cognitive domains. Build. Environ. 149, 253-263. https://doi. org/10.1016/j.buildenv.2018.12.002 (2019).

17. Zhu, Y. et al. Effects of illuminance and correlated color temperature on daytime cognitive performance, subjective mood, and alertness in healthy adults. Environ. Behav. 51, 199-230. https://doi.org/10.1177/0013916517738077 (2019).

18. Hopkins, S. et al. Blue-enriched lighting for older people living in care homes: Effect on activity, actigraphic sleep, mood and alertness. Curr. Alzheimer Res. 14, 1053-1062. https://doi.org/10.2174/1567205014666170608091119 (2017).

19. Chellappa, S. L. et al. Non-visual effects of light on melatonin, alertness and cognitive performance: Can blue-enriched light keep us alert?. PLoS ONE 6, e16429. https://doi.org/10.1371/journal.pone.0016429 (2011).

20. Hawes, B. K., Brunye, T. T., Mahoney, C. R., Sullivan, J. M. \& Aall, C. D. Effects of four workplace lighting technologies on perception, cognition and affective state. Int. J. Ind. Ergonom. 42, 122-128. https://doi.org/10.1016/j.ergon.2011.09.004 (2012).

21. Fotios, S. A revised Kruithof graph based on empirical data. Leukos 13, 3-17. https://doi.org/10.1080/15502724.2016.1159137 (2017).

22. Chellappa, S. L. et al. Non-visual effects of light on melatonin, alertness and cognitive performance: Can blue-enriched light keep us alert?. PLoS ONE https://doi.org/10.1371/journal.pone.0016429 (2011).

23. Knaier, R. et al. Morning bright light exposure has no influence on self-chosen exercise intensity and mood in overweight individuals-A randomized controlled trial. Chronobiol. Int. 35, 477-485. https://doi.org/10.1080/07420528.2017.1414828 (2018).

24. Duffy, J. F. \& Wright, K. P. Jr. Entrainment of the human circadian system by light. J. Biol. Rhythms 20, 326-338. https://doi. org/10.1177/0748730405277983 (2005).

25. Vandewalle, G. et al. Brain responses to violet, blue, and green monochromatic light exposures in humans: Prominent role of blue light and the brainstem. PLoS ONE 2, e1247. https://doi.org/10.1371/journal.pone.0001247 (2007).

26. Song, G. \& Zhang, K. Effects of driving fatigue on moods. Chin. J. Clin. Psychol. 14, 248-249. https://doi.org/10.3969/j.issn.10053611.2006.03.010(2006)

27. Vandewalle, G. et al. Spectral quality of light modulates emotional brain responses in humans. Proc. Natl. Acad. Sci. USA 107, 19549-19554. https://doi.org/10.1073/pnas.1010180107 (2010).

28. Prayag, A. S., Jost, S., Avouac, P., Dumortier, D. \& Gronfier, C. Dynamics of non-visual responses in humans: As fast as lightning?. Front. Neurosci. 13, 126. https://doi.org/10.3389/fnins.2019.00126 (2019).

29. Parrott, A. C. \& Joyce, C. Stress and arousal rhythms in cigarette smokers, deprived smokers, and nonsmokers. Hum. Psychopharm. Clin. 8, 21-28. https://doi.org/10.1002/hup.470080105 (1993)

30. Iskra-Golec, I. M., Wazna, A. \& Smith, L. Effects of blue-enriched light on the daily course of mood, sleepiness and light perception: A field experiment. Light. Res. Technol. 44, 506-513. https://doi.org/10.1177/1477153512447528 (2012).

31. Karuna, D., Susan, B., Kathryn, R., Wolfe, L. F. \& Zee, P. C. Light-induced changes of the circadian clock of humans: Increasing duration is more effective than increasing light intensity. Sleep https://doi.org/10.1016/j.seizure.2011.01.009 (2011). 
32. Arendt, J. Effects of light on human circadian rhythms. Reprod. Nutr. Dev. 39, 295-304. https://doi.org/10.1051/rnd:19990302 (1999).

33. Bedrosian, T. A. \& Nelson, R. J. Timing of light exposure affects mood and brain circuits. Transl. Psychiatry 7, e1017. https://doi. org/10.1038/tp.2016.262 (2017).

34. Kozaki, T., Miura, N., Takahashi, M. \& Yasukouchi, A. Effect of reduced illumination on insomnia in office workers. J. Occup. Health 54, 331-335. https://doi.org/10.1539/joh.12-0049-fs (2012).

35. Iskra-Golec, I. et al. Daytime effect of monochromatic blue light on EEG activity depends on duration and timing of exposure in young men. Adv. Cogn. Psychol. 13, 241. https://doi.org/10.5709/acp-0224-0 (2017).

36. Bradley, M. M. \& Lang, P. J. Measuring emotion: The self-assessment manikin and the semantic differential. J. Behav. Ther. Exp. Psychiatry 25, 49-59. https://doi.org/10.1016/0005-7916(94)90063-9 (1994).

37. Bonferroni, C. Teoria statistica delle classi e calcolo delle probabilit. Comm Firenze https://doi.org/10.1002/0471667196.ess1973 (1936).

\section{Acknowledgements}

This work was supported by National Key Research and Development Program of China 2018YFC0705100, Space Medical Experiment Project of China Manned Space Program, and the Scientific Foundation of Institute of Psychology, Chinese Academy of Sciences Y7CX432007.

\section{Author contributions}

L.C., F.-F.Y. and C.-B.H. designed the study, performed the data analysis and wrote the manuscript. L.C., S.F., Y.W., J.Y. and H.Y. performed the debugging and measurement of experimental parameters and collected data. All authors reviewed the manuscript.

\section{Competing interests}

The authors declare no competing interests.

\section{Additional information}

Correspondence and requests for materials should be addressed to F.-F.Y. or C.-B.H.

Reprints and permissions information is available at www.nature.com/reprints.

Publisher's note Springer Nature remains neutral with regard to jurisdictional claims in published maps and institutional affiliations.

(c) (i) Open Access This article is licensed under a Creative Commons Attribution 4.0 International

License, which permits use, sharing, adaptation, distribution and reproduction in any medium or format, as long as you give appropriate credit to the original author(s) and the source, provide a link to the Creative Commons licence, and indicate if changes were made. The images or other third party material in this article are included in the article's Creative Commons licence, unless indicated otherwise in a credit line to the material. If material is not included in the article's Creative Commons licence and your intended use is not permitted by statutory regulation or exceeds the permitted use, you will need to obtain permission directly from the copyright holder. To view a copy of this licence, visit http://creativecommons.org/licenses/by/4.0/.

(C) The Author(s) 2021 